\title{
Papilledema Due to Mirtazapine
}

\author{
Mehmet Emin Ceylan, Alper Evrensel, Gökçe Cömert
}

Department of Psychology, Üsküdar University School of Humanities and Social Sciences, İstanbul, Turkey

Background: Mirtazapine is a tetracyclic antidepressant that enhances both noradrenergic and serotonergic transmission. The most common cause of papilledema is increased intracranial pressure due to brain tumor. Also it may occur as a result of idiopathic intracranial hypertension (IIH, pseudo tumor cerebri). Moreover, papilledema may also develop due to retinitis, vasculitis, Graves' disease, hypertension, leukemia, lymphoma, diabetes mellitus and radiation.

Case Report: In this article, a patient who developed papilledema while under treatment with mirtazapine (30 $\mathrm{mg} /$ day) for two years and recovered with termination of mirtazapine treatment was discussed to draw the attention of clinicians to this side effect of mirtazapine.

Conclusion: Idiopathic intracranial hypertension and papilledema due to psychotropic drugs has been reported in the literature. Mirtazapine may rarely cause peripheral edema. However, papilledema due to mirtazapine has not been previously reported. Although papilledema is a very rare side effect of an antidepressant treatment, fundoscopic examinations of patients must be performed regularly.

Keywords: Antidepressant, mirtazapine, papilledema, side effect
Mirtazapine (Schering-Plough; New Jersey, USA) is a noradrenergic and specific serotonergic antidepressant. It enhances noradrenergic transmission through the central $\alpha 2$ adrenoceptor blockade and is a 5-HT2 and 5-HT3 receptor antagonist. Moreover, it increases serotoninergic message via the 5-HT1A receptor (1). Depending on the histamine 1 (H1) receptor antagonism, sedation, increased sleep and appetite occur, but there is no anticholinergic effect. Mirtazapine has side effects such as increased sleep and appetite, sedation, fatigue, hypotension, constipation, dry mouth; however, impairment of liver function and bone marrow suppression depend on granulocytopenia and gastrointestinal symptoms. Sexual side effects are relatively rarer. Peripheral edema has been reported due to the use of mirtazapine in the literature (2). In the literature, it has been reported that many drugs cause papilledema. These cases have the finding is that they have papilledema due to IIH in common. In our case, increased intracranial pressure was detected.

\section{CASE PRESENTATION}

Mirtazapine (30 mg/day) was initiated for a twenty-sixyear-old female patient with generalized anxiety disorder and comorbid depression. In the 24 month treatment period, she complained of blurred vision and loss of vision. She did not complain of diplopia, headache, nausea and vomiting. Her neurologic and ophthalmologic examinations were performed. On fundoscopic examination, bilateral papilledema was detected. Brain magnetic resonance imaging (MRI), electroencephalography (EEG), and lumbar puncture were performed. There was no increase in pressure within the head. Lumbar puncture (LP) opening pressure, cerebrospinal fluid (CSF) biochemistry, direct and painted examination and culture results were normal. She had no history of eye injury or eye surgery. Ocular blood pressure was normal. Routine biochemistry values were within normal limits. Arterial blood pressure values were measured as $120 / 80$. She had gained $4 \mathrm{~kg}$ in the previous two

Address for Correspondence: Dr. Alper Evrensel, Department of Psychology, Üsküdar University School of Humanities and Social Sciences, İstanbul, Turkey Phone: +905057130182 e-mail: alperevrensel@gmail.com

Received: 30 January $2015 \quad$ Accepted: 9 May 2015 • DOI: 10.5152/balkanmedj.2016.150151

Available at www.balkanmedicaljournal.org 
years, and her body mass index had increased from 20.32 to 21.82. No other cause of papilledema was found and for that reason mirtazapine treatment was terminated. Mianserin (20 $\mathrm{mg}$ /day) treatment was initiated. After that, papilledema recovered and optic disc returned to normal. Her complaints about blurred vision disappeared. Written informed consent was obtained from from the patient for this case report.

\section{DISCUSSION}

Papilledema occurs as a result of increased intracranial pressure. It develops by way of increased CSF pressure to the optic nerve. Two main reasons are suggested: first, the increased CSF pressure causes stasis in the central retinal vein; and second, axoplasmic flow of the optic nerve id blocked due to the increased pressure. Experimental studies have shown that papilledema is developed as a combination of these two conditions. In fundoscopic examination, deletion of the papillary border is seen. Patients have complaints such as blurred vision, diplopia and visual loss; headache, nausea and vomiting may also occur. These symptoms are more common in women and in obese individuals. The cause of papilledema is determined by laboratory investigations. Brain MRI, EEG, and LP should be used. If the cause of increased intracranial pressure cannot be identified despite all of the investigations, the patient is diagnosed with IIH. Idiopathic intracranial hypertension (IIH) is a clinical syndrome in which there is no abnormal finding in the brain and CSF and CSF pressure was determined to be over $200 \mathrm{mmH}_{2} \mathrm{O}$ (3). IIH and papilledema may occur depending on ocular, orbital, intracranial or systemic factors. In the literature, patients with idiopathic intracranial hypertension, and systemic corticosteroids, oral contraceptives, tetracycline, nalidixic acid, hypervitaminosis and lithium have been reported (4). The most common cause of papilledema due to psychotropic medications is lithium (4). There are also cases reports of papilledema depends on thioridazine treatment (5).

IIH may also develop secondary to weight gain, dependent on atypical antipsychotics. Yetimalar Beckmann et al. (6) reported that after gaining $16 \mathrm{~kg}$, a 38 -year-old female patient who used olanzapine, valproic acid and paroxetine developed papilledema secondary to $\mathrm{IIH}$, which disappeared with weight loss. Among antidepressants, sertraline is the only one that has been reported to cause papilledema. Hutcheon identified both papilledema and idiopathic intracranial hypertension during the examination of a 7-year-old boy who used sertraline and reported that after the termination of sertraline treatment, papilledema disappeared (7).
Post-receptor mechanisms caused by the stimulation of histamines (H1) and serotoninergic (5-HT2) receptors occur according to the increase of 1-4-5-inositol triphosphate (IP3) and diacylglycerol. An increase in IP3 leads to a rapid release of calcium while binding to the endoplasmic reticulum. The released calcium leads to activation of an ATP-dependent pump. Conversely, physiological blockade of these receptors by mirtazapine prevents the increase in IP3, which leads to down-regulation of the ATP-dependent pump. Secondary to all of these mechanisms, a decrease in smooth muscle contraction, vasodilatation and edema occur (8). Increases in cyclic adenosine monophosphate (cAMP) due to mirtazapine 5-HT2 receptor blockade cause relaxation in vascular smooth muscles (9). High plasma concentration of cAMP has been associated with idiopathic edema (10). With this mechanism, mirtazapine may lead to papilledema. In our case, IIH did not appear; the papilledema was not secondary to IIH. She was also not obese. Moreover, no ocular, orbital, intracranial or systemic cause was found. As a result, mirtazapine treatment was terminated due to it being the cause of papilledema. Thereupon, her symptoms of blurred vision and papilledema disappeared. The mechanism by which mirtazapine causes papilledema and why papilledema occurs in the $24^{\text {th }}$ month of the treatment are not clearly understood.

In conclusion, possible mechanisms may cause peripheral edema but may have been overlooked due to mild illness. Although papilledema is a very rare side effect of antidepressant treatment, fundoscopic examinations of patients must be performed regularly.

\section{Ethics Committee Approval: N/A.}

Informed Consent: Written informed consent was obteined from the patient.

Peer-review: Externally peer-reviewed.

Author contributions: Concept - M.E.C., A.E.; Design - M.E.C., A.E.; Supervision - M.E.C., A.E.; Resource - M.E.C., A.E., G,C.; Materials - A.E., G.C.; Data Collection and/or Processing - A.E., G.C.; Analysis and/or Interpretation - M.E.C., A.E., G.C.; Literature Search - A.E., G.C.; Writing - A.E., G.C.; Critical Reviews - M.E.C., A.E., G.C.

Conflict of Interest: No conflict of interest was declared by the authors.

Financial Disclosure: The authors declared that this study has received no financial support. 


\section{REFERENCES}

1. Alam A, Voronovich Z, Carley JA. A Review of Therapeutic Uses of Mirtazapine in Psychiatric and Medical Conditions. The Primary Care Companion for CNS Disorders 2013;15:PCC.13r01525.

2. Çam B, Kurt H. Mirtazapine bağlı periferik ödem: Olgu sunumu / Peripheral edema associated with mirtazapine: A case report. Anat J Psych 2013;14:84-8.

3. Binder DK, Horton JC, Lawton MT, McDermott MW. Idiopathic intracranial hypertension. Neurosurgery 2004;54:538-52. [CrossRef]

4. Spiteri MA, Geraint JD. Adverse ocular reactions to drugs. Postgrad Med J 1983;59:343-9. [CrossRef]
5. Blumberg AG, Klein DF. Severe papilledema associated with drug therapy. Am J Psych 1961;118:168-70. [CrossRef]

6. Yetimalar Beckmann Y, Seçil Y, Güngör BB. Pseudotumor cerebri in a patient being treated for bipolar disorder. General Hospital Psychiatry 2010;32:7-8. [CrossRef]

7. Hutcheon ML. An unexpected case of swollen optic nerves. Am $J$ Ther 2011;18:126-9. [CrossRef]

8. Katzung BG, Trevor AJ. Katzung \& Trevor's Pharmacology. $8^{\text {th }}$ ed. Stamford: Appleton\&Lange; 1998.

9. Barrett K, Brooks H, Boitano S, Barman S. Ganong's Review of Medical Physiology. 23th ed. Connecticut: Appleton\&Lange; 2010.

10. Kuchel O, Hamet P, Cuche JL, Tolis G, Fraysse J, Genest J. Urinary and plasma cyclic adenosine 3-5 monophosphate in patients with idiopathic edema. J Clin Endocrinol Metab 1975;41:282-9. [CrossRef] 